\title{
RAZONES PARA LA REINGENIERÍA DEL ESTADO DE DERECHO EN BOLIVIA Y PROPUESTAS PRELIMINARES PARA SU MODIFICACIÓN
}

\author{
Reasons for the re-engineering of the rule of law in Bolivia and preliminary \\ proposals for its modification
}

Luis Gonzalo Inarra Zeballos ${ }^{1}$

Recibido: 5 de marzo de 2020 - Aceptado: 20 de mayo de 2020

\section{RESUMEN}

El presente trabajo reflexivo busca demostrar la necesidad de una reingeniería del Estado de Derecho en Bolivia para posibilitar una mejor y más saludable democracia y hacer posible el "vivir en Constitución" (y no solo darse una Constitución) en la que los derechos humanos sean efectivamente ejercidos por los ciudadanos. Para eso se hará un repaso crítico a la última crisis política y social que el país ha vivido (2019), se analizarán los excesos del ejercicio del poder (hiperpresidencialismo), la efectiva inexistencia de frenos y contrapesos y los problemas del sistema de justicia, para luego arribar a propuestas preliminares que permitan modificar "la sala de máquinas de la Constitución".

Palabras clave: Estado de Derecho; Democracia; Hiperpresidencialismo; Derechos humanos; Bolivia.

\begin{abstract}
The present reflexive work seeks to demonstrate the need for a reengineering of the Rule of Law in Bolivia to enable a better and healthier democracy and to make "living in constitution" possible (and not only giving the citizens a Constitution) in which human rights are effectively exerted by the citizens. For this, a critical review will be made of the last political and social crisis that the country has experienced (2019), the excesses of the exercise of power (hyperpresidentialism), the effective absence of checks and balances, and also the problems of the justice system, to then arrive at preliminary proposals that allow modifying "the engine room of the Constitution".
\end{abstract}

Keywords: Rule of Law; Democracy; Hyperpresidentialism; Human rights; Bolivia.

\footnotetext{
${ }^{1}$ Profesor titular en las materias Derecho Internacional, Filosofía del Derecho y Derechos Humanos de la Universidad Mayor de San Simón y de otras universidades privadas, miembro del Instituto de Estudios Internacionales de Bolivia (IDEI). https://orcid.org/0000-0001-9470-4401, Email: 1.inarra@umss.edu.bo, luinarra@ gmail.com
} 


\section{Prefacio}

El interés por desarrollar el presente escrito surge principalmente de la situación de anomia política y de la crisis que ha vivido Bolivia recientemente y de la cual aún no ha logrado salir. En tal sentido, es nuestro principal propósito el explorar las bases que permitan encaminarnos hacia un «nunca más» repetir una crisis como la que principalmente se ha desarrollado en octubre y noviembre del año 2019 (Ferrajoli: 2013: 853 y ss.). Estamos conscientes de que este trabajo simplemente podría inaugurar un debate que es a todas luces urgente y necesario en los espacios académicos y políticos en Bolivia. (Luigi Ferrajoli refiere los "nunca más" como aquellas constituciones de la segunda posguerra que se erigieron con la finalidad de hacer todo por evitar en el futuro un nuevo holocausto y asegurar los derechos fundamentales).

Las bases de ese nunca más residen en la búsqueda de un mayor fortalecimiento del Estado de Derecho, que propenda a asegurar mayores frenos y contrapesos al ejercicio del poder, de tal forma que la democracia se vea fortalecida, al igual que los derechos humanos de la ciudadanía. Para demostrar esto, nos introduciremos en aspectos fáctico-políticos relacionados al accionar del gobierno de Evo Morales a fin de analizar aciertos y errores que se cometieron en su gestión y que llevaron a que la democracia se haya erosionado.

Inmediatamente, indagaremos en un concepto que permita acercarnos al cuadro teórico o modelo de Estado de Derecho que sugerimos construir para Bolivia, y podríamos decir que hasta para otros países. A partir del cual sea posible establecer un norte sobre el cual edificar nuestro razonamiento $\mathrm{y}$, fundamentalmente, permita a los bolivianos «vivir en Constitución», a diferencia del simple hecho de «darse una Constitución». Posteriormente, indagaremos sobre el hiperpresidencialismo y cómo éste juega en contra de los derechos humanos y su ejercicio ciudadano, incluyendo ejemplos de la realidad política boliviana para demostrar nuestras aseveraciones.

Por último, nos ocuparemos de presentar ciertas proposiciones elementales para encaminar el debate académico hacia pensar una reingeniería constitucional que haga posible una reforma del Estado boliviano para fortalecer una democracia más participativa y deliberativa.

\section{Estado de Derecho, democracia y derechos humanos ¿en Bolivia?}

En el año 2009 Bolivia aprobó mediante un referéndum o consulta popular una nueva Constitución Política del Estado, después de pasar por un complicado y conflictivo proceso para su elaboración. Este hecho es considerado un hito histórico en virtud de que por vez primera amplios sectores sociales del país fueron considerados en una Carta Magna y es parte de lo que los representantes del partido Movimiento al Socialismo (MAS) denominaron como la revolución democrática y cultural. De esta forma, se inició un nuevo ciclo constitucional en la historia boliviana con sendos auspicios de que esta vez la realidad política, social y económica comenzaría a mejorar para los bolivianos.

Es menester reconocer los aciertos y los errores de un gobierno como el de Evo Morales. Por primera vez se llevaron a cabo políticas inclusivas de los sectores históricamente 
excluidos, así como la participación de los representantes de comunidades y pueblos indígenas dentro de las diferentes esferas del Estado; es decir, a través de la Constitución, se dio voz a los sin voz; se reconoció y revalorizó a los pueblos indígenas mediante la constitucionalización de sus autonomías y del pluralismo jurídico. Asimismo, el PNUD (2019) expone los logros en materia económica y social que llevaron al país por varios años a estar entre los primeros sitiales respecto al crecimiento económico y humano dentro de la región latinoamericana (Bolivia es clasificado por primera vez como país de "Desarrollo Humano Alto") y a que, por ejemplo, los ingresos de la clase obrera hayan mejorado por efecto de los continuos incrementos de los salarios mínimo y básico. Sin embargo, así como se dieron estos y otros aciertos, también debemos considerar los errores que llevaron a la caída de su gobierno, no con el objeto de menospreciar una gestión que en su momento fue considerada como la mejor en la historia presidencial del país, sino con el propósito de develar las falencias estructurales del sistema democrático de Derecho que ha sido establecido por la actual Constitución y ha sido llevado a la práctica por el gobierno del MAS.

Son de conocimiento general los acontecimientos que se dieron sucesivamente y de manera progresiva, por lo menos desde que el Tribunal Constitucional Plurinacional (TCP) habilitó a Evo Morales, en el año 2013, para una nueva repostulación presidencial, hasta que en noviembre del año 2019 se produjera la caída de su gobierno (hechos que ampliaremos en los siguientes apartados), cuestión que vino a poner en tela de juicio la estabilidad, credibilidad y eficacia del sistema democrático y del Estado de Derecho.

\subsection{La erosión de la democracia y el debilitamiento del Estado de Derecho}

El profesor argentino Roberto Gargarella (2019) ha resaltado que en los últimos años algunos académicos provenientes de las disciplinas más diversas han hecho alusión a un «nuevo fenómeno», al que resumieron con la idea de «erosión democrática», que alude al «desgaste» que varios de los sistemas de gobierno han ido sufriendo «desde adentro», provocando lo que años atrás Guillermo O’Donnell (2007) había denominado como «muerte lenta», pues en tales situaciones no se advierte una «muerte abrupta» como en décadas pasadas ocurría con los golpes de Estado por parte de militares.

En ese sentido, Juan Linz (1978), autor que dedicó gran parte de su vida a conocer los peligros de perder la democracia, en su obra titulada La quiebra de las democracias, recalca la función de los políticos y demuestra que su actitud puede apuntalar la democracia o hacerla tambalear, llegando a proponer una prueba para identificar a los políticos antidemocráticos, aunque no llegó a desarrollarla del todo. Steven Levitsky y Daniel Ziblatt (2018, p. 32) recogen de Linz cuatro señales que ayudan a identificar a una persona autoritaria: 1) rechaza, ya sea de palabra o mediante acciones, las reglas democráticas del juego, 2) niega la legitimidad de sus oponentes, 3) tolera o alienta la violencia, o 4) indica su voluntad de restringir las libertades civiles de sus opositores, incluidos los medios de comunicación. Estos profesores de Harvard llegan a advertir que entre los presidentes que reúnen estas características se encuentra Evo Morales (Levitsky y Ziblatt, 2018: 33). No obstante, consideramos que en la historia boliviana también otros presidentes, quizá una mayoría de ellos, demostraron poseer algunas de las características señaladas. Esto también 
puede deberse a la cultura política autoritaria que impera en nuestra sociedad (Mansilla, 2010). Por tal razón, creemos que la erosión progresiva de la democracia no solamente se ha producido en el gobierno de Morales, sino que al parecer ha sido una constante de la política boliviana, lo que lleva a preguntarnos si evidentemente ha existido una verdadera democracia en el país. Cuestión que excede por mucho el objeto del presente trabajo.

Como ejemplo de lo anteriormente señalado, es posible observar que en la etapa de la democracia liberal a la cual Bolivia arribó en la década de los años 80 y duró hasta la asunción del gobierno del MAS (2005), la denominada «democracia pactada» provocaba que entre los denominados partidos políticos tradicionales de corte liberal se produjera una suerte de cuoteo donde buena parte de los mismos, inclusive «los más pequeños y marginales, pasaron en algún momento por el poder y algunos incluso llegaron a formar parte de gobiernos sucesivos como parte de coaliciones diferentes e incluso enfrentadas» (Iregui, 2012, p. 96), lo que en la realidad produjo una práctica prebendaria del poder y actitudes corruptas, de nepotismo, de abuso de poder y de malos manejos económicos del Estado, provocando que se incube lentamente la propia destrucción del sistema (Iregui, 2012: 97), es decir su muerte lenta. Este es un ejemplo donde encontramos un momento de erosión de la democracia, de la democracia liberal boliviana, más adelante veremos otro momento de erosión de la democracia provocada por el gobierno del MAS. Estas continuas erosiones a la postre terminarían provocando serias crisis: La democracia liberal con la crisis de 2003 y la democracia populista del MAS con la de 2019.

Ahora, antes de introducirnos en la erosión de la democracia populista del MAS, se hace necesario esclarecer qué entendemos por Estado de Derecho y cuál sería el Estado de Derecho que tuvo y tiene Bolivia. Por lo menos es necesario observar el modelo de Estado de Derecho al cual la actual Constitución aspira o se aproxima. Por su parte, es posible establecer que el Estado boliviano, en la era de la República simplemente aspiraba a constituir un modelo formal de Estado de Derecho, en el cual primaba: «la forma en que las leyes son promulgadas (si lo fueron por la persona autorizada, en la manera autorizada y apropiada), la claridad de la norma a seguir (si es suficientemente clara para guiar una conducta individual capacitando a la persona a planificar su vida) y la dimensión temporal de promulgación de las mismas (si es prospectiva o retrospectiva). Dichas concepciones formales, sin embargo, no juzgan el contenido de las leyes en sí mismas, de tal manera que cualquier consideración sobre su carácter justo resulta irrelevante» (Burgos, 2010, p. 232).

Esto debido a que la anterior Constitución no contenía un repertorio de derechos fundamentales detallado y amplio que se constituya en normas para limitar el poder de los órganos del Estado, dejando de esta forma mayor libertad al legislador ordinario.

Por su parte, aunque la anterior Constitución proclamaba su supremacía, en los hechos era entendida por el poder político y judicial solo como un instrumento de organización del Estado, quizás principalmente por no contener un amplio catálogo de derechos y un sistema de garantías o acciones de defensa judicial de los mismos, así como por no poseer un mecanismo más gravoso de modificación de su contenido, fuera del alcance del legislador ordinario (lo que vendría a ser la denominada rigidez constitucional). Elementos que la 
actual Constitución sí posee, lo que hace que se enmarque en un modelo sustancial de Estado de Derecho, mismo que «(...) incorpora gran parte de los atributos de los conceptos formales, pero sujeta las leyes y acciones administrativas a la garantía y realización de determinados derechos fundamentales constitucionalmente previstos. En términos de un Estado de Derecho sustancial se responde a la pregunta sobre 'qué' puede o debe mandarse en una sociedad. Antes que las formas que caracterizan a las leyes, lo importante es su contenido, el cual se debe medir según el respeto y garantía efectiva de una serie de derechos» (Burgos, 2010, pp. 232-233).

Así podríamos definir que el modelo de Estado de Derecho anterior constituía, en palabras de Luigi Ferrajoli (2013, pp. 298-299), un Estado «paleopositivista» de derecho, en el cual: «(...) el Derecho ya no es el (en ocasiones considerado) ontológicamente «verdadero» o «justo», sino todo y solo el establecido como tal por la ley. De aquí la subordinación del Derecho a la política (...) Puesto que la ley es producto de la política, el principio de la omnipotencia del legislador acabó por coincidir con la idea de la omnipotencia de la política y de su primacía sobre el Derecho (...)». Entonces, así definidas las cosas podríamos concordar que para este autor este modelo no constituye verdadero Estado de Derecho.

Ahora, por otra parte, el modelo que sí revestiría Estado de Derecho para el jurista italiano es el sustancial, donde gracias a la rigidez de las constituciones: «(...) también el poder legislativo se subordina al derecho; más precisamente, a la constitución como norma de reconocimiento del derecho válido, y no solo en lo relativo a las formas previstas para su producción sino asimismo en lo que hace a los contenidos producidos. En consecuencia, el legislador ya no es omnipotente, dado que las leyes no son válidas solo por estar en vigor, es decir, por haber sido producidas según las formas establecidas por las normas sobre su formación, sino solo si, además, son también coherentes con los principios constitucionales. Y tampoco es omnipotente ni siquiera la política, cuya relación con el derecho se complica y se invierte. El derecho es siempre «positivo», o sea, producido por la política como su propio instrumento. Y, sin embargo, en presencia de constituciones rígidas, será además normativo en relación con la política, que resulta así, a su vez, subordinada al derecho como instrumento de actuación de los principios y los derechos fundamentales constitucionalmente establecidos» (Ferrajoli, p. 300). Configurándose así una «esfera de lo indecidible» de los derechos por parte de la política.

Esta última concepción vendría a coincidir con la idea de que los derechos deben ser pensados como «cartas de triunfo» contra el poder de las mayorías (Dworkin, 1989) y, por lo tanto, no sometidos a la regla de la mayoría. Entonces en un marco jurídico como éste debería ser escasamente probable que los distintos poderes del Estado puedan provocar una alteración al Estado de Derecho, y de esa forma, la democracia y los derechos estarían debidamente resguardados y fuera del alcance de las mayorías. Sin embargo, particularmente nos parece que esta representa una concepción demasiado idealizada del Estado de Derecho, por no decir ingenua, al considerar que los poderes del Estado, en la práctica, mantendrán siempre incólume los derechos (Estoy consciente de que este modelo se mueve más en la lógica del deber ser del Derecho que en el ser), es decir, sin por lo menos interpretarlos cuando sean ambiguos o posean una textura abierta. Como bien 
distingue Gargarella (1996, p. 59), es insostenible pensar que los jueces solo hacen valer frente al legislador límites ya conocidos y preestablecidos en la Constitución, situación que pasa por alto la llamada «brecha interpretativa» o poder interpretativo de los jueces, que impide que la norma constitucional resuelva ex ante algunos de los problemas y desacuerdos que puedan surgir respecto a la delimitación de los derechos.

Lo propio piensa Jeremy Waldron (citado en Curcó, 2016, pp. 66 y 69), pero con relación a la política, puesto que considera que en esta lo que imperan son precisamente los desacuerdos y al propio tiempo, la necesidad de arribar a los mismos. De esta forma, la dificultad que se nos presenta radica en que «(...) si ya contamos con estándares independientes a la opinión mayoritaria para determinar el contenido de nuestras decisiones (de aquello que nos interesa proteger o garantizar), entonces la democracia (un procedimiento diseñado para superar los desacuerdos confiando la autoridad de decisión a la mayoría), sale sobrando».

De esta manera, al igual que Josep Aguiló (2010, p. 258), nos parece interesante y pertinente la concepción que Cass Sunstein (2006) plantea al referirse a los «acuerdos incompletamente teorizados». Este concepto a nuestro parecer responde con solvencia a la cuestión relativa a: «¿Cómo es posible que, en sociedades complejas y pluralistas, donde conviven concepciones del bien y de la justicia claramente divergentes entre sí, con un alto potencial de conflicto, etc., se alcance un acuerdo (un consenso) en torno a ciertas formas de acción y a ciertos criterios de legitimidad consistentes en valores y principios?». La respuesta referida estaría formulada de la siguiente manera: «Con mucha frecuencia la gente puede llegar a acuerdos sobre prácticas constitucionales, derechos y valores fundamentales incluso estando en un desacuerdo profundo sobre las concepciones de la Constitución o las concepciones de esos derechos y valores. El vínculo por medio del cual el constitucionalismo es posible no es otro que los llamados «acuerdos incompletamente teorizados». Estos acuerdos tienen la virtud de silenciar aquello en lo que se está en real y radical desacuerdo, y explicitar aquello en lo que se está de acuerdo. El acuerdo se alcanza a veces mediante procesos de abstracción y a veces mediante procesos de concreción, pero lo relevante es huir de aquello que radicalmente separa a los que participan en la convención constituyente. Por ejemplo, a veces en las constituciones se pueden encontrar normas que constituyen un acuerdo bastante concreto y cerrado y, sin embargo, es perfectamente posible que sea un acuerdo incompletamente teorizado. Es decir, que las razones por las cuales los participantes creen que una determinada práctica debe estar prohibida o debe estar permitida pueden diferir radicalmente».

Por ejemplo, los legisladores constituyentes pueden estar de acuerdo con que las personas tengan derecho a la identidad de género, como un concepto incompletamente teorizado, que permita arribar a un acuerdo general, dejando su especificación para una posterior actuación del legislador ordinario (en el caso de Bolivia vendría a ser la Ley de Identidad de Género que el TCP en parte declaró inconstitucional, de manera polémica). O a la inversa, la Constitución puede definir un concepto de forma específica (en forma de regla), como en el caso de la reelección presidencial permitiéndola o limitándola. Para el caso boliviano, la crítica vendría a darse en función a la pregunta isi este acuerdo ya fue 
especificado o «teorizado» por qué un órgano no mayoritario lo redefinió, más aún si consideramos que el límite a la reelección fue ratificado por una consulta popular el año 2016? Actitudes como ésta también provocaron la antes señalada «erosión democrática» en la cual los poderes del Estado cambiaron el sentido de las normas y acuerdos constituidos democráticamente por el soberano y por el constituyente.

Entonces, los acuerdos incompletamente teorizados nos permiten poner en primer plano el consenso básico al cual se puede arribar, y a partir del cual es posible construir una práctica jurídico-política centralmente discursiva o deliberativa. Es decir, nos permiten vivir en democracia: «vivir en Constitución». Pues como dice Aguiló, la presencia de conceptos polémicos es propia del ámbito de lo político, del ámbito en el que se manifiesta el conflicto político; en este sentido, es en el que pueden verse como el ring en el que se ventilan las principales disputas político-sociales (Aguiló, 2010, p. 259). Recordemos que Norberto Bobbio (1985, p. 129), por su parte, ha insistido en que todos los fenómenos políticos pueden ser analizados ex parte principis o ex parte populi, y que, como interpreta Aguiló, quizás Bobbio «(...) con ello probablemente trataba de significar no solo que las cosas se ven de manera diferente si se miran desde la perspectiva de quién tiene poder político que si se miran desde la perspectiva de quién está sometido al poder político, sino como algo más: que entre ambas perspectivas media una suerte de oposición dialéctica que hace difícil (sino imposible) su armonización total. Pues bien, en mi opinión, ahí está la clave principal para entender las múltiples discusiones internas del constitucionalismo. Es decir, el constitucionalismo y su componente de liberación política aminoran, si se quiere, las contradicciones típicas de todas las relaciones políticas, pero no las eliminan; y, en este sentido, las disputas internas del constitucionalismo no son más que una manifestación específica de un fenómeno más general» (Aguiló, 2010).

Este fenómeno vendría a ser el terreno de las contradicciones políticas y, por tanto, de la dialéctica y la deliberación. Aspecto que intentamos resaltar en este trabajo, como objetivo de toda democracia que considere el igual valor de todo ser humano, es decir, reconozca su autonomía individual y a partir de la cual, por medio de la deliberación, sea posible construir un autogobierno colectivo como las corrientes republicanas de la teoría política pretenden edificar: «El valor de la democracia no proviene solo del hecho de que sea un mecanismo de agregación de preferencias (eso en sí ya es relevante por cuanto es una forma de combatir la exclusión política), cuánto de que lo que se agregue sean preferencias transformadas como consecuencia de un debate público que toma en cuenta los intereses o preferencias de todos. Aunque no puedo detenerme en ello, tengo la impresión de que en muchas ocasiones cuando se recela de las relaciones entre Constitución regulativa y democracia no se entiende suficientemente al hecho de que la deliberación relevante requiere consensos básicos y de que, por tanto, no puede verse la democracia como un simple mecanismo de agregación de preferencias» (Aguiló, 2010: 260).

Como veremos en los acápites siguientes, la erosión de la democracia y del Estado de Derecho en Bolivia, como mencionamos al inicio de este apartado, se debe en gran forma al autoritarismo de los gobiernos. Es decir, al exceso de poder de los presidentes y al rechazo de entablar los diferentes temas sociales mediante procesos dialógicos y 
RAZONES PARA LA REINGENIERÍA DEL ESTADO DE DERECHO EN BOLIVIA Y PROPUESTAS PRELIMINARES PARA SU MODIFICACIÓN

deliberativos, en un plano de horizontalidad, inclinándose en su lugar, de manera contraria y tendenciosa a la verticalidad y centralidad del poder en detrimento de la democracia y los derechos.

\subsection{Una organización y ejercicio del poder hostil hacia los derechos: el hiperpresidencialismo}

La Constitución boliviana de 2009, como señalamos anteriormente, posee una gran y extensa relación de normas sobre derechos humanos que, como ya vimos, son parte fundamental del modelo sustancial del Estado de Derecho al que la Constitución aspira por lo menos en el plano teórico. A esto se suma la inclusión constitucional de tratados internacionales de derechos humanos en el «bloque de constitucionalidad» (art. 410.II), como una forma de establecer límites al poder del Estado, también desde el Derecho Internacional de los Derechos Humanos. Es decir, estas normas internacionales coadyuvan en la tarea de establecer límites a los poderes del Estado, principalmente al presidencialismo o hiperpresidencialismo reinante en la historia boliviana.

Sin embargo, como bien hace notar Gargarella (2014, p. 286) la idea de la auto operatividad de las cláusulas constitucionales que reconocen derechos va acompañada de la idea ingenua de que bastan ciertos artículos en la Constitución para que estos cobren vida, se autoejecuten, cuando más bien, en su criterio, lo que ocurre es precisamente lo contrario: «finalmente cualquier cláusula nueva se inserta en un contexto político, institucional, constitucional, existente, que puede ser hospitalario o no con las novedades que recién aparecen». O sea, en los países latinoamericanos al receptarse cada vez mayores normas sobre derechos humanos en sus ordenamientos, parece sugerir la idea de que la maquinaria del poder se acomoda suficientemente a los mismos e incluso los hace eficaces.

Este imaginario no puede ser sino contrario a la realidad imperante en los países latinoamericanos, siendo que especialmente en Bolivia ha campeado a lo largo de su historia un «hiperpresidencialismo» hostil hacia los derechos humanos. Debemos al jurista Carlos Nino (1992) este concepto, puesto que en su obra Fundamentos de Derecho Constitucional expuso que el hiperpresidencialismo, al referirse a la presidencia hipertrofiada, según la Constitución argentina de 1853, se refiere a que: «Esta somera revisión de las facultades que los presidentes fueron adquiriendo por una interpretación extensiva de cláusulas constitucionales, por claudicación de los otros poderes del Estado, o por un ejercicio liso y llano de la musculatura política, muestra que, desde el punto de vista normativo, el presidente argentino es, como lo preveía Alberdi, un verdadero monarca, aunque a diferencia de lo que él suponía, sus facultades regias no han sido óbice para la inestabilidad de los gobiernos y los abusos de poder frente a los derechos de los ciudadanos. También se confirma, con la desvirtuación del espíritu y muchas veces de los textos constitucionales, en la concesión y asunción de facultades extraordinarias por parte del presidente, la tendencia a la ajuridicidad que ha sido una constante en nuestra práctica político-institucional, aún en períodos de jure» (Nino, 1992 p. 529). De esta forma, esta presidencia hipertrofiada, va provocando el debilitamiento del congreso de un país, del sistema de los partidos políticos y del sistema electoral, del proceso de sumisión de la administración de justicia a la Constitución y a las leyes, la declinación relativa del 
federalismo (en el caso boliviano el debilitamiento de las autonomías o impedimento de su despegue) y las formaciones corporativas.

Veremos ahora, en el caso boliviano y específicamente en relación al gobierno de Evo Morales (Estamos conscientes de que en la salida de Evo Morales del poder se conjugaron varios elementos, principalmente las manifestaciones que lograron paralizar el país desde el 21 de octubre hasta mediados de noviembre de 2019, incluso después de su salida; el informe de auditoría de la OEA a las elecciones del 20 de octubre, que causó un impacto demoledor en la credibilidad social del Órgano Electoral Plurinacional y del propio gobierno de Morales, generando un pedido social para su renuncia; y, paralelamente, el accionar de grupos cívico-políticos, el amotinamiento de la Policía Nacional y la "recomendación" de renuncia al presidente por parte de las Fuerzas Armadas, lo cual provocó la denuncia de un golpe de Estado), cómo estos últimos aspectos de la institucionalidad boliviana fueron debilitándose progresivamente, hasta llegar a la erosión de la democracia y del Estado de Derecho, y en última instancia, se produzca la crisis democrática que terminó con el gobierno del MAS:

\section{a) La falta de frenos y contrapesos y la debilidad del órgano legislativo}

En la línea de las concepciones sobre el Estado de Derecho que hemos señalado antes, es pertinente aquí referirnos a una de las definiciones que Bobbio (2006, p. 18) ha establecido: «(...) un Estado en el que los poderes públicos son regulados por normas generales (las leyes fundamentales o constitucionales) y deben ser ejercidos en el ámbito de las leyes que los regulan, salvo el derecho del ciudadano de recurrir a un juez independiente para hacer reconocer o rechazar el abuso o exceso de poder. Entendido así, el Estado de Derecho refleja la vieja doctrina que se remonta a los clásicos y que fue transmitida por las doctrinas políticas medievales, de la superioridad del gobierno de las leyes sobre el gobierno de los hombres, según la fórmula Lex facit regem». Estamos hablando de un Estado en el cual se establece la existencia de un aparato institucional, legal y de control del espacio público que promueva la legalidad y restrinja la impunidad. Es decir, un Estado en el cual haya un sistema de control y de accountability (rendición de cuentas), de separación efectiva de los poderes del Estado y por lo tanto de cuestiones que van mucho más allá de la mera decisión de los que gobiernan (Iraegui, 2012, p. 103).

Pese a que, como Iraegui identifica: «Bolivia llegó a la democracia sin antecedentes previos efectivos de separación de poderes y de control de la actividad pública y, en ese sentido, todo estaba por construir, comenzando por una cultura política que terminase con la idea de que los políticos podían gobernar en medio de la impunidad y la arbitrariedad» (Iraegui, p. 104), la solución a este problema tendría que haber llegado con la implementación de la actual Constitución, principalmente en virtud a las normas constitucionales que proscriben la concesión de facultades extraordinarias y la acumulación del poder público prohibiendo la otorgación de poderes por los cuales los derechos y garantías reconocidos constitucionalmente queden a merced de un determinado órgano o persona (art. 140. I y II), así como la disposición constitucional que organiza el Estado en cuatro órganos fundamentándolo en la independencia, separación, coordinación y cooperación de los 
mismos, estableciendo nuevamente la imposibilidad de reunir las funciones de cada uno en un solo órgano ni delegarlas entre sí (art. 12. I y III).

En los hechos esta normativa, pese a las buenas intenciones que el legislador constituyente tuvo, en el terreno de la política y su aplicación no pasaron de ser cartas de buenas intenciones. Como Iraegui reconoce, el gobierno de Morales se constituyó por ser un gobierno populista (advertimos que el populismo aquí no tiene un sentido ni negativo ni positivo, es simplemente una locución que trata de describir un conjunto de hechos), por dos elementos fundamentales: 1) por la ampliación del sistema político y la inclusión de los sectores populares en un proceso de expansión sustantiva de la representación y, 2) por la devaluación del carácter liberal de la democracia o, dicho en otros términos, por el incremento evidente de las prácticas políticas de contenido autoritario y, como consecuencia, por una evidente desvalorización de los derechos políticos y civiles.

Caracterizándose además por el: «(...) fuerte liderazgo carismático, el ensalzamiento discursivo del cambio y el desdén por el pasado, la reacción antiliberal, el desprecio hacia la intermediación política, la desinstitucionalización, el peso relativo de la estructura partidaria, la emergencia político-gubernamental de movimientos sociales que son incluidos en la política, la aversión por las élites, el desdén hacia lo intelectual, la permanente apelación directa al pueblo como personificación de todos los atributos morales positivos y la lucha contra un enemigo (interno o externo) que pretende la ruptura de la unidad virtuosa del pueblo. Además, (...)-como algo positivo- una importante tendencia a promover derechos sociales y una genuina preocupación por la situación de los grupos sociales menos favorecidos, lo que, por supuesto, es una constante del populismo como manifestación de la existencia de grupos marginados emergentes» (Iraegui. pp. 154-157).

En un escenario como éste, donde además el órgano ejecutivo posee extensos poderes o atribuciones (27 en total, art. 172 de la CPE,), sumado a que participa como eje central en las vastas competencias privativas y exclusivas del nivel central del Estado (60 en total, art. 298 de la CPE), indiscutiblemente llega a consolidarse un hiperpresidencialismo, que en el caso del gobierno del MAS se vio fortalecido por el dominio de dos tercios en la Asamblea Legislativa Plurinacional, eliminando así cualquier atisbo de control y fiscalización, que en la práctica fue más formal que real, en la medida que no existió suficiente autonomía de los legisladores ni la capacidad de la oposición para contrarrestar el poder del gobierno (Iraegui, p. 192). La crítica que Iraegui (2012) a su juicio efectúa es la: «(...) total subordinación de los parlamentarios al ejecutivo y su tendencia a votar masivamente y sin el más mínimo espíritu crítico las normas que llegan del gobierno». Sin embargo, también reconoce que: «(...) No parece evidente que el actual legislativo sea más o menos dependiente de lo que fueron las versiones existentes durante el segundo ciclo liberal, la fiscalización continúa siendo muy endeble y el modelo presidencial sigue en vigencia»

\section{b) El órgano judicial y el Ministerio Público dominados por el hiperpresidencialismo}

Como bien señala Jorge Lazarte (1991, p. 595), entre las instituciones que menos confianza ha generado tradicionalmente en la población boliviana se encuentra con claridad el poder 
judicial. Ante tal situación, siempre ha sido apremiante su reforma estructural, y como no podía ser de otra manera, el gobierno del MAS asumió dicha responsabilidad con la finalidad de promover mayor justicia para la población boliviana.

Sin embargo, paradójicamente su accionar más bien llevó a un total descrédito social del mismo, por las constantes interferencias que tuvieron jueces y magistrados por parte del gobierno. Principalmente, por las sentencias constitucionales que éste obtuvo a su favor para habilitar la repostulación del presidente y vicepresidente, siendo la más polémica, conflictiva y resistida la sentencia constitucional 0084/2017, por interpretar el artículo 23 del pacto de San José de Costa Rica en el sentido de que el mismo no contiene un límite a la repostulación, siendo, por tanto, más favorable para las autoridades ejecutivas, con lo cual estableció la inaplicabilidad del artículo 168 de la Constitución y la inconstitucionalidad de las normas de la Ley del Régimen Electoral que limitan la reelección a una sola vez, habilitando así a las autoridades ejecutivas a una repostulación indefinida y, lo que es peor, inaplicó la voluntad de la mayoría del pueblo boliviano expresada en el referéndum del 21 de febrero de 2016 que reafirmó el tenor del citado artículo 168 constitucional.

La dependencia de los magistrados respecto al poder político es evidente en virtud a que, por más que los mismos sean elegidos democráticamente por el pueblo, las listas de precandidatos son elaboradas y constituidas por el órgano legislativo, en el cual el MAS, como ya sabemos, tiene dos tercios de votos. Por otra parte, además de estas intromisiones en el órgano judicial, es bastante conocida la instrumentalización del Ministerio Público, cuyo Fiscal General fue designado por la Asamblea Legislativa dominada por el MAS, lo que en los hechos facilitó que se haya presentado el denominado fenómeno de la «judicialización de la política», produciéndose persecuciones y juzgamientos a los opositores al gobierno.

Nótese, que actualmente el gobierno de la presidente Jeanine Añez también está haciendo uso de los excesivos poderes que el sistema presidencialista le confiere para perseguir y detener a autoridades y funcionarios del anterior gobierno, incidiendo inclusive en lo que sus adversarios en su momento también incurrieron, en una sistemática vulneración a los derechos, garantías y libertades de quienes no comparten sus ideas políticas. Con esto no queremos afirmar que en ningún caso se deben procesar a ex autoridades y ex funcionarios, simplemente pretendemos advertir que en muchos casos el hiperpresidencialismo también puede instrumentalizar la administración de justicia conculcando garantías constitucionales dentro de los procesos judiciales.

\section{c) El órgano electoral y los conflictos posteriores a la elección presidencial}

Al otorgarle la Constitución a la Asamblea Legislativa la atribución de designar a seis vocales y al presidente del Estado la potestad de designar a uno de ellos (art. 206. III), sumado a los dos tercios del MAS y al "escaso esfuerzo oficial por lograr candidatos de consenso, significó que se generalizase la idea de que todos los nuevos magistrados eran afines al MAS, idea que se profundizó tras filtrarse imágenes del presidente de la CNE, Wilfredo Ovando, participando en mítines electorales del partido de gobierno" (Iraegui, 
2012, p. 202). Esta idea de afinidad de los vocales y de la injerencia del gobierno en sus funciones perduró e inclusive, a la postre, se profundizó en diversos sectores de la sociedad boliviana con la habilitación del binomio electoral Evo Morales - Álvaro García, como candidatos de las pasadas elecciones presidenciales del 20 de octubre de 2019.

La historia de las intromisiones e injerencias del gobierno del MAS que, como dijimos, para muchas personas era algo evidente, terminaron con los trágicos eventos posteriores a los mencionados comicios electorales, dando por resultado más de una treintena de personas fallecidas y varias decenas de heridos. El 11 de noviembre de 2019, el presidente Morales y su vicepresidente García renunciaron a sus cargos después de que la OEA publicara su informe preliminar sobre la auditoría a las elecciones, advirtiendo irregularidades, lo que para un gran sector de la población no fue otra cosa más que la confirmación de sus sospechas de fraude electoral.

Más allá de si hubo o no fraude en las pasadas elecciones, ya que es un tema que también excede las pretensiones de este trabajo, el uso autoritario del poder nos deja la lección de que cuando un sector de la población sospecha u observa que parte de sus libertades y derechos están siendo conculcados, como el derecho a elegir o el derecho de participar de forma equitativa en procesos eleccionarios (que se ve seriamente limitado cuando una autoridad es candidata y hace uso de recursos del Estado en su favor), no solo la democracia se erosiona o quiebra por dentro, sino que el Estado de Derecho, que resguarda los derechos de los ciudadanos ingresa en una aguda crisis, no quedándole quizás a la población otro recurso que recurrir a la protesta en las calles y tomar medidas de presión que terminan por desestabilizar por completo el sistema institucional del Estado.

\section{A modo de conclusión: el «nunca más» y la correlativa necesidad de separar «esferas»}

Cualquier crisis del Estado boliviano casi siempre ha tenido que ver con el presidente, si éste se excede en el ejercicio del poder, si éste no actúa conforme a los requerimientos de la sociedad o si se enfermaba o renunciaba, en todos esos casos siempre se presentaban y presentan problemas de gobernabilidad y de autoridad estatal. Es el caso que nos tocó vivir a los bolivianos tras la renuncia de Morales y de las autoridades que se encuentran en la línea de sucesión constitucional. Entonces, esto lleva a pensar que en el sistema político boliviano existe demasiada dependencia de la figura presidencial y del órgano ejecutivo como tal, pues muy bien se puede comenzar a analizar, en base a estas experiencias, la posibilidad de establecer sistemas parlamentaristas o semi-presidencialistas.

Lo que aquí nos preocupa es establecer un «nunca más» a las crisis como la que Bolivia ha atravesado y seguirá haciéndolo si no se remedian o se reinventan las estructuras de control al poder (al hiperpresidencialismo, principalmente). Por eso nos permitimos proponer la necesidad de efectuar lo que Giovanni Sartori (1999) denominó «reingeniería constitucional» para que desde las academias jurídica y política se postulen propuestas de reformas a lo que Gargarella (1996) denomina «sala de máquinas de la Constitución», con dos propósitos fundamentales: 1) proponer un nuevo sistema presidencialista para caracterizar una nueva forma de gobierno que haga efectivo el control de sus funciones y 
que en circunstancias de ausencia de poder se adopte un sistema parlamentario para superar crisis de gobernabilidad, o por otro lado, que en última instancia se analice la posibilidad de desechar a los presidentes, o en definitiva de instituir un sistema parlamentarista o semipresidencialista, 2) se organice la sala de máquinas de tal forma que el poder se encuentre al servicio de las personas y posibilite el bienestar y satisfacción de las necesidades de la población.

Para el primer propósito señalado se requiere el establecimiento de un sistema efectivo de frenos y contrapesos que asegure lo más posible el control y equilibrio del poder estatal para resguardar principalmente las libertades o derechos negativos de las personas. Para el segundo propósito, la adopción de una nueva forma de organización estatal que implemente instituciones de garantía de los derechos sociales o derechos positivos, en los que el poder del gobierno no tenga mayor influencia que la de posibilitar los recursos necesarios para que dichas instituciones cumplan con sus responsabilidades.

De esta manera, las «esferas de justicia» de Michael Walzer (1983) podrán hacerse factibles impidiendo la injusticia, la cual llega a generarse cuando: «(...) en todos los casos en que los poseedores legítimos de los bienes en una esfera convierten estos últimos en bienes dentro de otras esferas y, así, terminan por estar en posesión de bienes en múltiples esferas, obtenidos de un modo que no está en correspondencia con los criterios distributivos y, por ende, no es coherente con los significados sociales de los bienes», de esta forma: «la injusticia es, en estricto sentido, la tiranía (dominancia) de los depredadores de bienes sociales que cruzan y violan las fronteras entre esferas y se proponen la conversión general de recursos propios de arenas sociales distintas y diferenciadas. Una sociedad es una sociedad de igualdad compleja donde está obstaculizada la convertibilidad universal de bienes específicos» (Veca, 2010, p. 104). Así, es justo que la separación de poderes y la instauración de frenos y contrapesos efectivos sean implementados, de la misma manera en que deban hacerlo las instituciones político-sociales regidas por criterios de justicia distributiva que se encarguen de facilitar a la población un acceso igualitario a los recursos sociales y económicos.

Solo de esta manera podremos aspirar a una concepción republicana más robusta del Estado de Derecho, donde para Fernando Calderón (2002, p. 85): «El Estado en un régimen democrático no se identifica con el mercado. La función Estatal es proteger y fomentar la participación de los ciudadanos. El Estado en un mundo globalizado debe potenciar la capacidad de sus ciudadanos, tanto en el plano técnico-instrumental -es decir, del manejo de los nuevos códigos de conocimiento-, como en el de la socialización democrática, referida a instituciones, a valores sustantivos y al reconocimiento de la diversidad étnicacultural, como referente de la acción política estatal». De esta forma, quizá sea posible aspirar a un ejercicio deliberativo y más participativo de la sociedad donde ésta ejerza un control del Estado en un plano más horizontal.

Entonces, es posible proponer, inicialmente, y principalmente para el debate académico en Bolivia, y también en los países latinoamericanos, dos técnicas: una referida a la fragmentación del poder y la otra al control inter órganos (checks and balances). La 
primera, ad intra, referida a la fragmentación de las funciones de las entidades miembro del Poder Ejecutivo (ministerios y dependencias), en el sentido de que cada entidad sea relativamente autónoma con relación al Presidente, con funciones y atribuciones bien definidas, que sean acordes a los diferentes tipos de derechos humanos y que tengan la finalidad de garantizar a la población el disfrute de los mismos; v.gr. un ministerio autónomo (o semi autónomo) de la vivienda que trabaje planes y proyectos y que los ejecute en favor de las personas de escasos recursos económicos, y que cada cierto tiempo tenga que rendir cuentas no al presidente (o no solo) sino a la sociedad civil.

Según la segunda técnica, ad extra, los checks and balances podrían funcionar de mejor manera si constitucionalmente se establecen mayores límites y controles principalmente al órgano ejecutivo, V.gr. un mecanismo judicial que obligue al Tribunal Constitucional a revisar de oficio la constitucionalidad de ciertos actos del gobierno (decretos principalmente), y por otra parte, se faculte al órgano legislativo la revisión de la legalidad de los mismos, dándoles a ambos órganos un plazo razonable para el efecto, lo cual posibilitaría que el ejecutivo se encuentre en una relación de estricta sujeción a la Constitución y a la ley, generándose así un doble control.

Esta sujeción en teoría debería producirse sin necesidad de mayores controles, pero la realidad política de Bolivia, tal como demostramos en el presente escrito, así como la realidad de varios otros países latinoamericanos, exige que desde la academia jurídica se continúen debatiendo posibles reformas al Estado de Derecho.

\section{REFERENCIAS BIBLIOGRÁFICAS}

Aguiló, J. (2010). Sobre las contradicciones (tensiones) del constitucionalismo y las concepciones de la constitución. En El canon neoconstitucional, Carbonell, Miguel y García Jaramillo, Leonardo (Editores). Madrid, España: Ed. Trotta.

Bobbio, N. (1985). El futuro de la democracia. Barcelona, España: Plaza y Janés.

Bobbio, N. (2006). Liberalismo y democracia. Ciudad de México, México: Fondo de Cultura Económica.

Burgos, J. (2010). Estado de Derecho: del modelo formal al sustancial. En Revista Diálogos de Saberes, julio-diciembre de 2010, págs. 231 a 244. Recuperado de: https://dialnet.unirioja.es/descarga/articulo/3618626.pdf

Calderón, F. (2002). La reforma de la política: deliberación y desarrollo. La Paz, Bolivia: FES-ILDIS.

Congreso Nacional de Bolivia. Constitución Política del Estado. Febrero 7 de 2009.

Curcó, F. Constitucionalismo y democracia: una revisión crítica del argumento contraepistémico. En Revista Isonomía, $\mathrm{N}^{\circ}$ 44, abril de 2016. Recuperado de: http://www.scielo.org.mx/pdf/is/n44/1405-0218-is-44-00063.pdf 
Dworkin, R. (1989). Los derechos en serio. Madrid, España: Editorial Ariel S.A.

Ferrajoli L. (2013). Principia Iuris. Teoría de la Democracia. Madrid, España: Trotta.

Gargarella, R. (1996). La justicia frente al gobierno. Sobre el carácter contramayoritario del poder judicial. Barcelona, España: Editorial Ariel.

Gargarella, R. (2014), La sala de máquinas de la Constitución. Buenos Aires, Argentina: Katz Editores.

Gargarella, R. El desencanto con las democracias que mueren por dentro. Artículo del periódico La Nación del 22 de noviembre de 2019. Recuperado de: https://www.lanacion.com.ar/opinion/columnistas/el-desencanto-con-las-democraciasque-mueren-por-dentro-nid2308624

Iraegui, A. (2012). La democracia en Bolivia. La Paz, Bolivia: Plural Editores.

Lazarte, J. Partidos, democracia, problemas de representación informalización de la política (el caso de Bolivia). En Revista de Estudios Políticos (Nueva Época). Núm. 74, octubre-diciembre de 1991. Recuperado de: https://dialnet.unirioja.es/descarga/articulo/27120.pdf

Levitsky, S. y Ziblatt, D. (2018). Cómo mueren las democracias. Bogotá, Colombia: Editorial Ariel.

Linz, J. (1996). La quiebra de las democracias. Madrid, España: Alianza Editorial.

Mansilla, H. La cultura política en Bolivia. La posibilidad del populismo autoritario, En Revista de Estudios Políticos (Nueva Época), Núm. 21, septiembre-diciembre de 2010. Recuperado de: DOI: http://dx.doi.org/10.22201/fcpys.24484903e.2010.21.24184

Nino, C. (1992). Fundamentos de Derecho Constitucional. Buenos Aires, Argentina: Editorial Astrea.

O’Donnell, Guillermo. Las crisis perpetuas de la democracia. En Revista Polis, vol. 3, n. 1, enero-junio 2007. Recuperado de: http://www.scielo.org.mx/scielo.php?script=sci_arttext\&pid=S1870$\underline{23332007000100002}$

Programa de las Naciones Unidas para el Desarrollo (PNUD). Informe sobre Desarrollo Humano 2019: Más allá del ingreso, más allá de los promedios, más allá del presente: desigualdades del desarrollo humano en el siglo XXI. Bolivia es clasificado por primera vez como país de "Desarrollo Humano Alto". 9 de diciembre de 2019. Recuperado de: https://www.bo.undp.org/content/bolivia/es/home/presscenter/articles/2019/bolivia-esclasificado-por-primera-vez-como-pais-de-desarrollo-h.html 
Sartori, G. (1999). Ingeniería Constitucional comparada: una investigación de estructuras, incentivos y resultados. Ciudad de México, México: Fondo de Cultura Económica.

Sunstein, C. R. (2006). Acuerdos carentes de una teoría completa en Derecho Constitucional. En Precedente, Revista Jurídica, p. 31-49. Recuperado de: https://doi.org/10.18046/prec.v0.1423

Tribunal Constitucional Plurinacional de Bolivia. Sentencia $N^{\circ} 003 / 2013$. Sentencia por la cual se habilita a Evo Morales para postularse a una nueva elección presidencial. Abril 25 de 2013.

Tribunal Constitucional Plurinacional de Bolivia. Sentencia $N^{\circ}$ 0084/2017. Acción de inconstitucionalidad abstracta planteada por diputados del gobierno. Diciembre $12 \mathrm{de}$ 2017.

Veca, S. (2010). La filosofía política. Buenos Aires, Argentina: Amorrortu Editores.

Walzer, Michael. (1983). Las esferas de la justicia: una defensa del pluralismo y la igualdad. Nueva York: Basic books. 